\title{
Papers
}

\section{Routine protein energy supplementation in adults: systematic review}

\author{
Jan Potter, Peter Langhorne, Margaret Roberts
}

\begin{abstract}
Objectives: To determine whether routine oral and enteral nutritional supplementation can improve the weight, anthropometry, and survival of adult patients. Design: Systematic review of randomised controlled trials of oral or enteral protein supplementation in adults. Trials were identified from Medline (Silver Platter 3.11, 1966-96), reference lists of identified studies and review articles, and communication with feed manufacturers.

Subjects: Randomised controlled trials comparing oral or enteral protein supplementation with no routine supplementation. All trials of adult subjects were included except those addressing nutrition in pregnancy.
\end{abstract}

Main outcome measures: Change in body weight and anthropometry (mid-arm muscle circumference), and all cause case fatality recorded at the end of scheduled follow up. Body weight and anthropometry were analysed as the weighted mean difference and $95 \%$ confidence intervals of the percentage change in these variables. Case fatality was analysed with odds ratio and $95 \%$ confidence intervals.

Results: 32 eligible reports (2286 randomised patients) published between February 1979 and July 1996 were identified, of which 30 (93.8\%) (2062 randomised patients) reported outcomes of interest. Case fatality data were available for $1670(81 \%)$ patients, and continuous variable data for up to 1607 $(78 \%)$ patients. The treatment group receiving routine nutritional supplementation showed consistently improved changes in body weight and anthropometry compared with controls; weighted mean difference $2.06 \%(95 \%$ confidence interval $1.63 \%$ to $2.49 \%)$ and $3.16 \%(2.43 \%$ to $3.89 \%)$ respectively. The pooled odds ratio for death in the treatment group was $0.66(0.48$ to $0.91,2 \mathrm{P}<0.01)$. Apparent benefits were observed in several prespecified subgroups of patients,

treatment settings, and interventions, but were not evident if trials with less robust methodology were excluded.

Conclusions: Routine oral or enteral supplementation seems to improve the nutritional indices of adult patients, but there are insufficient data in trials which meet strict methodological criteria to be certain if mortality is reduced. Benefits were not restricted to particular patient groups. Further large pragmatic randomised controlled trials of routine nutritional supplementation are justified.

\section{Introduction}

Malnutrition is a common and underrecognised problem in hospital patients. ${ }^{1-4}$ Furthermore, illness and hospitalisation are frequently associated with negative energy balance and further deterioration in nutritional status. ${ }^{5}$ A recent survey of admissions to a general hospital reported a prevalence of malnutrition of $27 \%$ to $46 \%$ across various hospital specialties. ${ }^{2}$ Many studies have reported distinct associations between undernutrition and impaired immune function, increased sepsis, impaired wound healing, impaired muscle function and strength, and increased mortality. ${ }^{16-11}$

When the high prevalence and potentially deleterious effects of undernutrition are considered it is not surprising that many trials have examined the effects of nutritional supplementation in various patient groups. Several trials have shown that poor immune function and poor muscle function can be reversed by nutritional supplementation..$^{6} 7^{912-16}$ However, there is no practical consensus among clinicians on the value of routine nutritional supplementation ${ }^{24}$ or on how this could be achieved.

We evaluated the existing evidence on the effectiveness of routinely prescribed oral or enteral protein energy supplements (table A on website) in improving body weight, anthropometry, and survival of adult patients.

\section{Subjects and methods}

\section{Inclusion criteria}

To determine whether the routine provision of oral or enteral protein energy supplementation improved outcome in adult patients we established the following inclusion criteria for trials: (a) randomised controlled trial, $(b)$ oral or enteral protein energy supplementation, (c) control group receiving placebo or no intervention, and (d) human adult subjects (including all age groups and baseline nutritional states but excluding trials in pregnancy).

\section{Identification of trials}

We conducted a Medline search (Silver Platter 3.11) from January 1966 to November 1996 . To identify the maximum number of randomised trials we used a
Victoria Geriatric
Unit, Victoria
Infirmary NHS
Trust, Glasgow
G41 3DX
Jan Potter,
consultant physician
Margaret Roberts,
consultant physician
Academic Section
of Geriatric
Medicine,
Department of
Medicine,
University of
Glasgow, Glasgow
Royal Infirmary
Trust, Glasgow
G4 0SF
Peter Langhorne,
senior lecturer
Correspondence to:
DrJ Potter,
Department of
Medicine for the
Elderly,
Mansionhouse Unit,
Victoria Infirmary
NHS Trust,
Glasgow G41 3DX
BMJ 1998;317:495-501

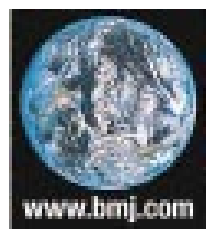

Additional data can be found on our website 
broad search stategy with the mesh word nutrition, which was not restricted to English language citations. Where publication type "trial" and study group "human" were available these were also selected. In addition we carried out manual reference searching of all identified articles and reviews on nutritional supplementation. We also asked colleagues and manufacturers of supplement feeds to identify any unpublished material.

Most studies could be excluded from reading the abstract. Studies that could not clearly be excluded in this way were reviewed. The assessment of trial eligibility was done by two independent assessors (JP and MR) who reviewed the introduction and methods blinded to the results and discussion. Disagreements between assessors were decided by an independent reviewer (PL).

\section{Data extraction}

We gathered baseline information for each trial on the number and age of patients studied, diagnoses and severity of illness, the type and duration of the intervention, study design, method of randomisation, completeness of follow up, and outcome measures recorded.

The primary trials reported body weight and anthropometric measures in several ways. To allow us to collate standardised information on the change in body weight during the trial periods we selected the mean and SD of the percentage change in weight. This strategy was used because we believed it had clinical relevance-that is, reflected the degree of weight change-and was likely to be available from many trials. Where percentage weight change was not available we calculated the difference between the initial and final body weight, expressed as a percentage of baseline weight, and inferred a SD of $10 \%$. The SD value was a conservative one that was at the upper limit of any of the observed results. If a baseline weight was not reported we assumed a standard value of $60 \mathrm{~kg}$, which applied to all patients regardless of their baseline nutritional status. We chose mid-arm muscle circumference as the anthropometry measure. Where this was not described in a trial we derived it from the mid-upper arm circumference and triceps skin fold thickness using standard formulas. ${ }^{18}$ Anthropometry data were then pooled as per weight data.

\section{Statistical analysis}

A fixed effects approach (Peto method) was used to calculate the odds ratio and $95 \%$ confidence intervals for case fatality, ${ }^{19}$ and the findings were confirmed using an alternative (random effects) approach. ${ }^{20}$ Weighted mean difference and 95\% confidence intervals were calculated using a fixed effect approach for changes in weight and anthropometry measures. These results were confirmed using alternative measures (standard effect sizes) and statistical approaches (random effects model). ${ }^{21}$

We carried out analyses of prespecified subgroups on the basis of certain patient and intervention characteristics. Patient characteristics included: patient group (healthy volunteers or ill patients), baseline body mass index $(<25$ th centile or $>25$ th centile), mean study population age $(<70$ or $>70$ years), specialty group (medical or surgical specialties), and underlying disease (malignant or non-malignant). Intervention characteristics included: method of delivery and type of nutritional supplement provided (oral sip feed, oral natural feed, nasogastric feed, percutaneous endoscopic gastrostomy tube), quantity of supplemented calorie intake $(<400$ or $>400$ calories per day), and duration of intervention ( $<35$ and $>35$ days).

\section{Results}

We identified 94 potentially eligible trials from the abstract, and of these, 62 were excluded: 24 (25.5\%) were not randomised controlled trials, $13(13.8 \%)$ considered total parenteral nutrition, 19 (20.2\%) did not use a control group as defined by our inclusion criteria, and six $(6.4 \%)$ were perinatal trials. Therefore $32(34 \%)$ trials fulfilled all entry criteria. Two $(6.2 \%)$ of these $\operatorname{trials}^{22}{ }^{23}$ did not report any outcomes of interest (table B on website), leaving 30 (32\%) trials for analysis (table 1). No unpublished trials were identified that fulfilled our inclusion criteria.

A total of 2062 patients were available for analysis from the 30 trials. These trials covered a wide range of clinical variables including inpatients, outpatients, surgical and medical disorders, malignant and nonmalignant diseases, and young and elderly groups. In addition, although all the trials used either oral or enteral nutritional supplementation they varied in the route of delivery, the amount of additional kilocalories given, and the duration of intervention (table 1). Twenty $(66.7 \%)$ trials evaluated oral supplementation, seven $(23.3 \%)$ nasogastric tube feeding, and three $(10.0 \%)$ percutaneous endoscopic gastrostomy feeding. Six (20\%) trials used a stratified randomisation design according to aspects of the patients' clinical characteristics. The individual strata of these trials have been analysed separately.

The methodological characteristics of the trials varied (table 1$)$; nine $(30.0 \%)$ had clearly concealed randomisation and complete follow up (category A), $21(70.0 \%)$ did not report the randomisation procedure of which $11(52.4 \%)$ had complete follow up (category B), and $10(33.3 \%)$ had incomplete follow up (category C). Only four (13.3\%) trials reported a clearly blinded assessment of outcomes.

\section{Change in weight}

Twenty six $(86.6 \%)$ trials provided data on weight change for $1607 / 1648(97.5 \%)$ patients. The absolute weight change tended to be negative particularly in studies incorporating surgical interventions or treatment of malignancies. In almost all trials, however, there was a greater percentage weight gain or smaller percentage weight loss in the supplemented group than in the controls (fig 1). The pooled weighted mean difference for weight change showed benefit from supplementation $(2.06 \%$, 95\% confidence interval $1.63 \%$ to $2.49 \%$ ), but was complicated by heterogeneity. The results still showed benefit from supplementation when an alternative random effects ${ }^{20}$ model was used $(3.11 \%, 2.03 \%$ to $4.20 \%)$ or if the standardised mean difference was calculated $(0.50,0.40$ to 0.60$)$.

The conclusions were similar (weighted mean difference $2.85 \%, 1.03 \%$ to $4.68 \%$ ) if the analysis was restricted to the most methodologically rigorous trials (category A) or to those trials where no inferences were required regarding baseline weights or SDs $(3.39 \%$, $2.12 \%$ to $4.66 \%)$. 
Table 1 Trials included in systematic review

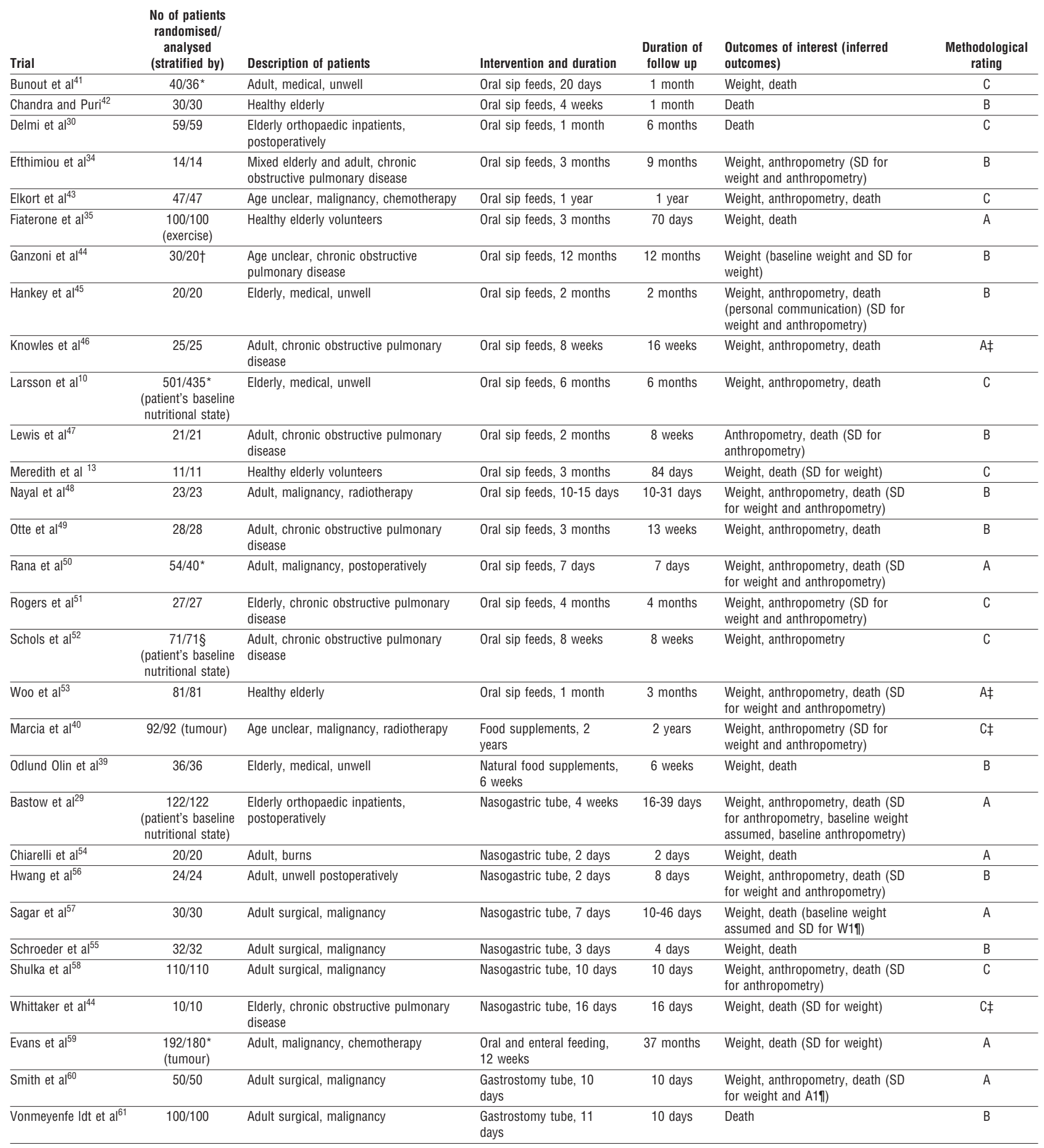

Adult $=<70$ years; elderly $=\geqslant 70$ years; $A=$ method of randomisation clearly described and complete follow up; $B=$ no method described but stated as randomised and complete patient follow up; $\mathrm{C}=$ no method described and not all patients accounted for at end of follow up.

*Withdrawn after randomisation and before treatment (see sensitivity analysis).

†Analysed fewer than randomised reasons unclear.

$\ddagger$ Anthropometry assessed by observer blinded to patients’ treatment allocation group (if not stated assume not blinded)

§Part of larger study with other non-nutritional arms.

ISD for weight (W1) or anthropometry (A1) calculated from median and range provided.

\section{Change in anthropometry}

Seventeen $(56.7 \%)$ trials reported changes in anthropometric measures for 1209/1230 (98.3\%) patients. In most trials the treatment group showed improved anthropometric measures compared with the control group. The pooled result showed considerable heterogeneity and gave a pooled weighted mean difference of $3.16 \%$ (95\% confidence interval $2.43 \%$ to $3.89 \%$ ), which was unchanged when a random effects statistical approach was used $(3.27 \%, 1.74 \%$ to $4.80 \%)$. Reanalysis using the standardised mean difference confirmed these results $(0.36,0.24$ to 0.48$)$. 


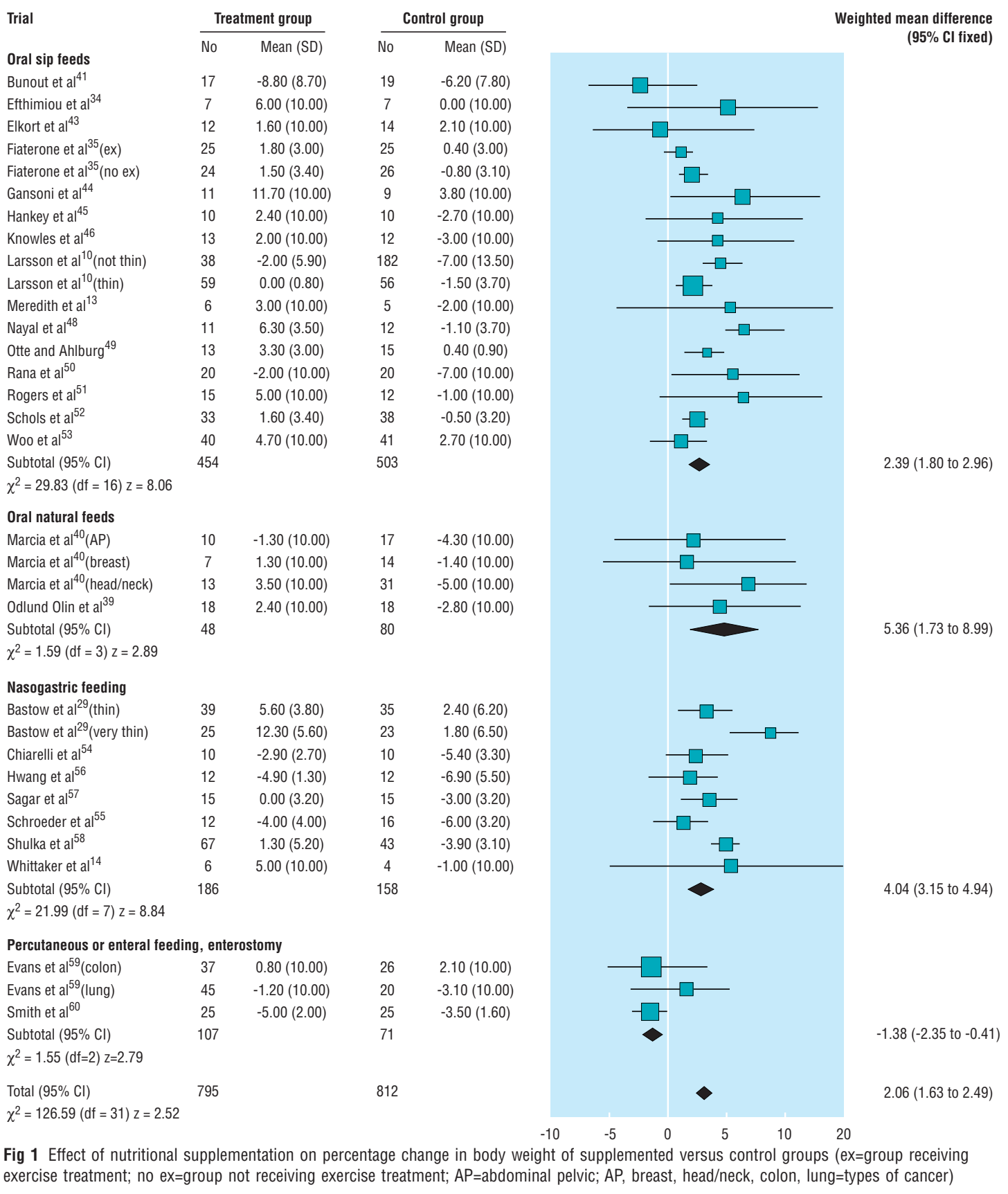

Conclusions were similar if the analysis was restricted to methodological category A trials (weighted mean difference $3.00 \%, 1.93 \%$ to $4.06 \%$ ) or trials where no inferences were required regarding baseline weights or SDs $(2.73 \%, 1.81 \%$ to $3.66 \%)$.

Table 2 Sensitivity analyses of duration of follow up in association with odds of death

\begin{tabular}{lcc} 
Duration of follow up & Odds ratio & $\mathbf{9 5 \%}$ Cl \\
\hline $0-2$ weeks & 1.25 & 0.50 to 3.13 \\
\hline $2-4$ weeks & 0.41 & 0.08 to 2.07 \\
\hline $1-3$ months & 0.77 & 0.32 to 1.83 \\
\hline $3-6$ months & 0.53 & 0.34 to 0.83 \\
\hline$>6$ months & 0.78 & 0.36 to 1.72 \\
\hline
\end{tabular}

Case fatality-Case fatality data were available from $25(83.3 \%)$ trials (1670 patients). The pooled odds ratio for death by the end of scheduled follow up (fig 2) showed a reduced case fatality in treatment compared with control groups of 0.66 (0.48 to $0.91,2 \mathrm{P}<0.01)$, with no significant statistical heterogeneity $\left(\chi^{2}=11.67 ; \mathrm{df}=13 ; \mathrm{P}>0.2\right)$. However, the exclusion of trials which did not meet the highest methodological criteria (category A) reduced this result to a non-significant trend $(\mathrm{P}>0.1)$ in favour of supplementation (odds ratio $0.81,0.44$ to 1.50 ). Comparable results for category $\mathrm{B}$ and $\mathrm{C}$ trials were 1.48 (0.43 to 5.09$)$ and 0.55 (0.47 to 0.90$)$ respectively. Recalculation of results to include a best and worst case scenario for the missing data from the cat- 
egory B and C trials did not substantially change the conclusions.

\section{Subgroup and sensitivity analysis}

Analyses were carried out for several subgroups that met prespecified criteria. Trials that provided inadequate information for inclusion in a subgroup were omitted from the analysis. Subgroups included: (a) patients that were well (community dwelling, healthy volunteers, $n=111$ ) or unwell (major operation, acute hospital admission, or chronic long term care resident, $\mathrm{n}=697$ ), (b) patients that were originally well nourished (body mass index $>25$ th centile, $\mathrm{n}=510$ ) or undernourished $(<25$ th centile, $\mathrm{n}=298),(c)$ patients with malignant $(n=210)$ or non-malignant disease $(\mathrm{n}=917),(d)$ mean age of study population $>70$ years $(\mathrm{n}=813)$ or $<70$ years $(\mathrm{n}=731)$, (e) patients being treated by surgical $(n=205)$ or medical $(n=1595)$ specialists, $(f)$ energy value of treatment given and consumed $>400 \mathrm{kcal}$ per day $(\mathrm{n}=624)$ or $<400 \mathrm{kcal}$ per day $(\mathrm{n}=184)$, and $(\mathrm{g})$ duration of intervention $>35$ days $(n=627)$ or $<35$ days $(n=181)$.

Within the limitations of the available data, analysis of the subgroups (fig 3) showed that the benefits of routine nutritional supplementation were not restricted to particular subgroups or trials.

In addition to the characteristics considered above, the trials varied widely in the length of scheduled follow up. Although the duration of follow up sometimes differed from the duration of intervention (table 1), follow up was more consistently reported in the primary trials. A sensitivity analysis based on the duration of follow up did not show any clear association with the odds of death (table 2).

Further sensitivity analyses were carried out to assess the potential influence of publication bias and of the assumptions included in our calculations. These analyses indicated that about 1500 patients in trials with neutral results (odds ratio 1) would be sufficient to render the observed reduction in case fatality non-significant $(2 \mathrm{P}>0.05)$.

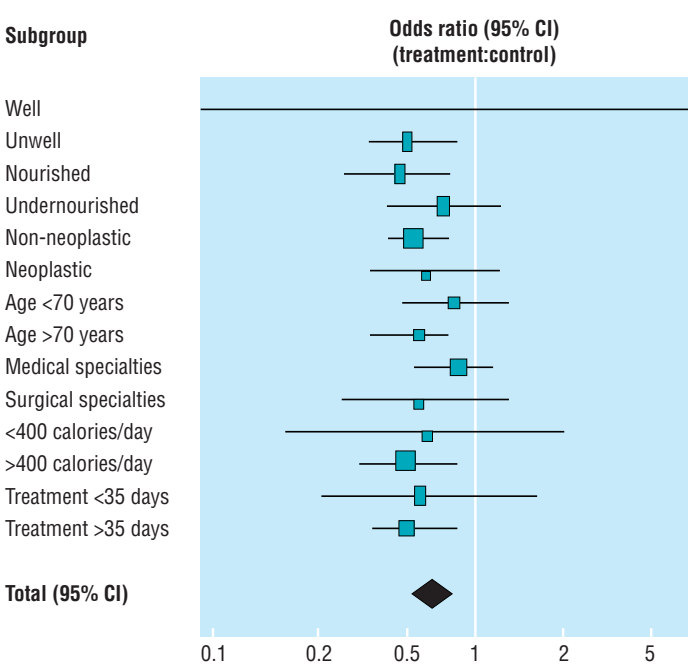

Fig 3 Subgroup analysis on effects of supplementation on case fatality. Data are for case fatality in supplemented group as opposed to controls stratified by trial characteristics

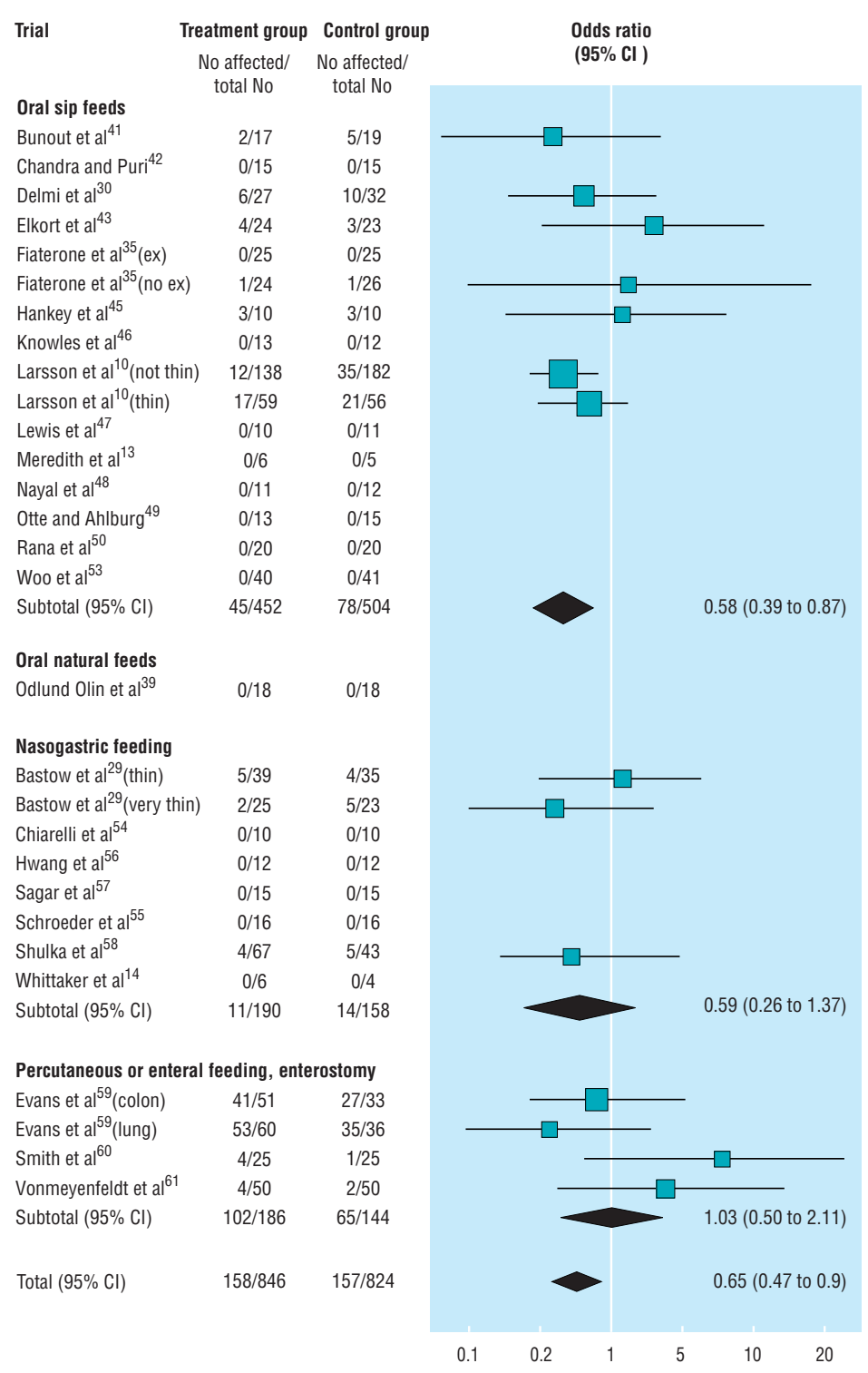

Fig 2 Effect of nutritional supplementation on case fatality in supplemented versus control groups. Case fatality recorded at end of scheduled follow up (median 2 months, interquartile range 10 days to 6 months)

\section{Discussion}

We wanted to address the hypothesis that adult patients whose diet was routinely supplemented with additional enteral protein calories would, on average, be more likely to benefit from improved nutritional indices (body weight and anthropometry) and improved survival. If such a benefit could be observed in a diverse group of trials, it would suggest that protein calorie supplementation is generally beneficial. As we were interested in potentially simple and routinely applicable interventions we considered trials of both enteral and oral supplementation. The results suggest that routine supplementation in a variety of patient groups and clinical settings will improve body weight and anthropometry. Weight and anthropometric measures are validated measures of nutritional status, ${ }^{24-28}$ and improvements in these measures have been shown to be associated with improvements in a 
number of clinical outcomes. ${ }^{92}{ }^{20}$ Positive energy balance and weight gain have been associated with improvements in immune function and sepsis and improvements in muscle bulk resulting in better muscle function, strength, and functional independence. ${ }^{71-35}$ These improvements could have important benefits on clinical outcomes. This analysis has not, however, shown an unequivocal effect of nutritional supplementation in reducing case fatality; the apparent benefits could be explained by publication bias $^{36}$ or less reliable trial methodologies. ${ }^{37}$

Much of the recent controversy over the usefulness of systematic review and meta-analysis ${ }^{38}$ centres on publication bias-that is, the selective non-publishing of neutral or negative trials. We have attempted to identify unpublished work by several methods including discussions with colleagues and manufacturers of nutritional supplements. It is impossible, however, to guarantee identification of all trials, and a few neutral or negative trials could overturn our conclusions.

Another problem is the ability of the reviewers to assess the methodological quality of the trials, in particular the security of randomisation and the completeness of follow up, both of which may influence results. ${ }^{37}$ Although all the trials reported that they were randomised, only nine $(30.0 \%)$ clearly described a secure, concealed procedure (category A). A further 11 (category B) may have used a secure procedure and seemed to have complete follow up; however, it was impossible to ascertain this from the published reports. In the remainder (category $\mathrm{C}$ ) there were occasionally marked or unexplained discrepancies between the number of patients in the treatment and control arms, or a number of patients were unaccounted for at the end of follow up.

Further limitations are that only a minority $(n=4$, $13.3 \%$ ) of trials commented on whether outcome assessments were carried out in a clearly unbiased manner-that is, by observers blinded to treatment allocation. This is important for weight and anthropometry outcomes which may also be biased by the number of subjects unavailable for follow up. It might be speculated that more deaths in the control arm may have led to an underestimate of the degree of weight loss, but it is impossible to know with certainty. Many other secondary outcomes of interest-for example, muscle strength or length of stay, were not reported in most of the papers.

Although the benefits of nutritional supplementation were observed across all subgroups it is interesting to note that rather more elderly people than young adults have been studied, and that for each outcome they seemed to benefit as much as their younger counterparts. This may be important as protein calorie undernutrition is more common in the elderly ${ }^{2}$ who make up the majority of hospital admissions and frequently have a longer period of illness and longer hospital stay putting them at the greatest risk of continued nutritional depletion.

If our conclusions are not secure beyond reasonable doubt does this really matter? Although no one would argue against providing high quality food in hospitals the question really concerns the routine provision of manufactured nutritional supplements. Only two of the trials studied the use of natural food supplements to achieve improvement in protein and calorie
- Undernutrition is common in patients admitted to hospital, and hospitalisation frequently results in further nutritional depletion

- Undernutrition is associated with increased morbidity and mortality, but clinicians remain to be convinced that routine nutritional supplementation improves outcomes

- This systematic review indicates that significant improvements in nutritional status and reductions in case fatality occurred when protein calorie supplements were routinely given to adults in several clinical situations

- Conclusions were influenced by the methodological quality of the primary trials

- Further large pragmatic randomised trials are justified

intake. ${ }^{39}$ Most of the trials used sip feeds, the composition of which varies but generally contains protein and calories in variable proportions but with the same quantities of vitamins and minerals found in the energy equivalent of a well balanced diet. As such it is likely that nutritional supplementation given as sip feeds is not associated with significant problems or side effects. Insertion of feeding tubes does carry a small risk but is often indicated for reasons (for example dysphagia) other than supplement provision alone. Even if the potential risks of nutritional supplementation are low, however, there are still implications in terms of cost or organisation, or both, if nutritional supplementation were to become a routine part of hospital prescribing. These costs would have to be considered against the potential benefits of preventing deteriorations in weight, muscle bulk, function, strength, and immunity, by improved energy balance. ${ }^{6} 7$ 12-16

\section{Conclusion}

Oral and enteral protein energy nutritional supplementation may be associated with improvements in weight gain and anthropometry and significant reductions in case fatality. However, there remain considerable uncertainties about these conclusions. We conclude that large pragmatic randomised controlled trials of routine oral or enteral nutritional supplementation are justified.

We thank Dr John Reilly and Professor M Lean for their comments on the manuscript, Catherine Hankey for providing unpublished data, and Fiona Clark for providing information on nutritional products.

Contributors: JP was responsible for the study design, literature search, assessing trial eligibility, data analysis, and drafting the paper; she will act as guarantor for the paper. PL was responsible for the study design, assessing trial eligibility, data analysis, and drafting the paper. MR was responsible for assessing trial eligibility and drafting the paper.

Funding: None.

Conflict of interest: None.

1 Potter JM, Klipstein K, Reilly JJ, Roberts MA. The nutritional status and clinical course of acute admissions to a geriatric unit. Age Ageing 1995;24:131-6.

2 McWhirter JP, Pennington CR. Incidence and recognition of malnutrition in hospital. BMJ 1994;308:945-9.

3 Allison SP. Malnutrition in hospital patients. Hospital Update 1995; Feb: $55-60$. 
4 Lennard-Jones JE. A positive approach to nutrition as treatment. London: Kings Fund, 1992.

5 Klipstein-Grobusch K, Reilly JJ, Potter JM, Edwards CA, Roberts MA Energy intake and expenditure in elderly patients admitted to hospital with acute illness. Br J Nutr 1995;73:323-40.

6 Chandra RK. The relation between immunology, nutrition and disease in elderly people. Age Ageing 1990;19:25-31.

7 Fiatarone MA, Evans WJ. The etiology and reversibility of muscle dysfunction in the aged. J Geriatr 1993;48:77-83

8 Galanos AN, Pieper CF, Cornoni-Huntley C, Bales CW, Fillenbaum GG. Nutrition and function: is there a relationship between body mass index and the functional capabilities of community dwelling elderly? J Am Geriatr Soc 1994:42:368-73.

9 Lopes J, Russell D, Whitwell J, Jeejeebhoy KN. Skeletal muscle function in malnutrition. Am J Clin Nutr 1982;36:602-10.

10 Larsson J, Unosson M, Ek AC, Nilsson L, Thorsland S, Bjurulf P. Effect of dietary supplementation on nutritional status and clinical outcome in 501 geriatric patients-a randomised study. Clin Nutr 1990;9:179-84.

11 Lesourd B. Protein undernutrition as the major cause of decreased immune function in the elderly: clinical and functional implications. Nut Rev 1995;53:S86-94

12 Russell D McR, Prendergast P, Darby PL, Garfinkel PE, Whitwell J, Jeejeebhoy KN. A comparison between muscle function and body composition in anorexia nervosa: the effect of refeeding. Am J Clin Nutr 1993;38:229-37.

13 Meredith CN, Frontera WR, O'Reilly KP, Evans WJ. Body composition in elderly men: effect of dietary modification during strength training. J Am Geriatr Soc 1992;40:155-62.

14 Whittaker JS, Ryan F, Buckley PA, Road JD. The effects of refeeding on peripheral and respiratory muscle function in malnourished chronic obstructive pulmonary disease patients. Am Rev Respir Dis 1990;142: 283-6.

15 Roebothan BV, Chandra RK. Relationship between nutitional status and immune function of elderly people. Age Ageing 1994;23:49-53.

16 Gross PA, Quinnan GV, Rodstein M, LaMontagne JR, Kaslow RA, Saah AJ, et al. Association of influenza immunization with reduction in mortality in an elderly population. Arch Intern Med 1988;148:562-5.

17 Souba WW. Enteral nutrition after surgery: not routinely indicated in well nourished patients. BMJ 1996;312:864

18 Burr ML, Phillips KM. Anthropometric norms in the elderly. Br J Nutr 1984;51:165-9

19 Peto R. Why do we need systematic overviews of randomised trials? Stat Med 1987;6:233-40.

20 DerSimonian R, Laird N. Meta-analysis in clinical trials. Contr Clin Trials $1986 ; 7: 177-88$.

21 Bracken MB. Statistical methods for analysis of effects of treatment in overviews of randomised trials. In: Sinclair JC, Bracken MB, eds. Effective care of the newborn infant. Oxford: Oxford University Press, 1992;13-18.

22 Bunker VW, Stansfield MF, Deacon-Smith R, Marzil RA, Hounslow A Clayton BE. Dietary supplementation and immunocompetence in housebound elderly subjects. Br J Biomed Sci 1994;51:128-35.

23 Spirtos NM, Ballon SC. Needle catheter jejunostomy: a controlled prospective randomised trial in patients with gynecologic malignancy. Am J Obstet Gynecol 1988;158:1285-90.

24 Vir CS, Love AHG. Anthropometric measurements in the elderly. Gerom tology $1980 ; 1: 3-8$

25 Reilly JJ, Murray A, Wilson J, Durnin JVGA. Measuring the body composition of elderly subjects: a comparison of methods. Br J Nutr 1994;72: 33-44.

26 Heymsfield SB, McManus C, Smith J, Stevens V, Nixon DW Anthropometric measurement of muscle mass: revised equations for calculating bone-free arm muscle area. Am J Clin Nutr 1982;36:680-90

27 Baker JP, Detsky AS, Wesson DE, Wolfman SL, Stewart S, Whitehall J, et al. Nutritional assessment: a comparison of clinical judgement and objective measures. N Engl J Med 1982;306:969-72.

28 Jebb SA, Murgatroyd PR, Goldberg GR, Prentice AM, Coward WA. In vivo measurement of changes in body composition: description of methods and their validation against 12-d continuous whole-body calorimetry. $A m$ J Clin Nutr 1993;58:455-62.

29 Bastow MD, Rawlings J, Allison SP. Benefits of supplementary tube feeding after fractured neck of femur: a randomised controlled trial. $B M J$ 1983;287:1589-92

30 Delmi M, Rapin CH, Bengoa JM, Delmans PD, Vasey H, Bonjour JP. Dietary supplementation in elderly patients with fractured neck of femur. Lancet 1990;335:1013-6.

31 Chandra RK. Effect of vitamin and trace element supplementation on immune responses and infection in elderly subjects. Lancet 1992 340:1124-7.

32 Windsor JA, Hill GL. Risk factors for postoperative pneumonia. Ann Surg 1988;209-14.

33 Kelly SM, Rosa A, Field S, Coughlin M, Shizgal HM, Macklem PT. Inspiratory muscle strength and body composition in patients receiving total parenteral nutrition therapy. Am Rev Respir Dis 1984;130:33-7.

34 Efthimiou J, Fleming J, Gomes C, Spiro SG. The effect of supplementary oral nutrition in poorly nourished patients with chronic obstructive pumonary disease. Am Rev Respir Dis 1988;137:1075-82.

35 Fiatarone MA, Oneill EF, Doyleryan N, Clements KM, Solares GR, Nelson $\mathrm{ME}$, et al. Exercise training and nutritional supplementation for physical frailty in very elderly people. N Engl J Med 1994;330:1769-75.

36 Egger M, Davey Smith G, Schneider M, Minder C. Bias in meta-analysi detected by a simple, graphical test. BMJ 1997;315:629-34.

37 Shulz KE, Chalmers I, Hayes RJ, Altman D. Empirical evidence of bias JAMA 1995;273:408-12.

38 Chalmers I, Altman DG. Systematic reviews. London: BMJ Publishing Group, 1995.
39 Odlund Olin A, Osterberg P, Hadell K, Armyr I, Jerstom S, Ljungqvist O. Energy enriched hospital food to improve energy intake in elderly patients. J Parenter Enteral Nutr 1996;20:93-7.

40 Marcia E, Moran J, Santos J, Blanco M, Mahedero G, Salas J. Nutritiona evaluation and dietetic care in cancer patients treated with radiotherapy: prospective study. Nutrition 1991;7:205-9.

41 Bunout D, Mcardi V, Hirsch S, Petermann M, Kelly M, Silva G, et al. Nutritional support in hospitalised patients with alcoholic liver disease. Eur J Clin Nutr 1989;43:615-21.

42 Chandra RK, Puri S. Nutritional support improves antibody response to influenza vaccine in the elderly. BMJ 1985;291:705-6.

43 Elkort RJ, Baker FL, Vitale JJ, Cordano A. Long term nutritional support as an adjunct to chemotherapy for breast cancer. J Parenter Enteral Nut 1981;5:385-90.

44 Ganzoni A, Heilig P, Schonenberger K, Hugli O, Filling JW, Brandli O. High calorie nutrition in chronic obstructive airways disease. Schwei Rundsch Med Prax 1994;83:13-6.

45 Hankey CR, Summerbell J, Wynne HA. The effect of dietary supplementation in continuing care elderly people: nutritional, anthropometric and biochemical parameters. J Hum Nutr Diet 1993;6:317-22.

46 Knowles JB, Fairbairn MS, Wiggs BJ, Chan-Yan C, Pardy RL. Dietary supplementation and respiratory muscle performance in patients with COPD. Chest 1988;93:979-83.

47 Lewis M, Belman MJ, Dorr-Uyemura L. Nutritional supplementation in ambulatory patients with chronic obstructive pulmonary disease. Am Rev Respir Dis 1987;135:1062-8.

48 Nayal H, El-Ghoneimy E, El-Haddad S. Impact of nutritional supplementation on treatment delay and morbidity in patients with head and neck tumors treated with irradiation. Nutrition 1992;8:13-8.

49 Otte KE, Ahlburg P, D'Amore F, Stellfeld M. Nutritional repletion in malnourished patients with emphysema. J Parenter Enteral Nutr 1989;13:152-6.

50 Rana SK, Bray J, Menzies-Gow N, Jameson J, Payne J, Frost P, et al. Short term benefits of post-operative dietary supplements in surgical patients. Clin Nutr 1992;11:337-44.

51 Rogers RM, Donahoe M, Constantino J. Physiologic effects of ora supplemental feeding in malnourished patients with chronic obstructive pulmonary disease: a randomised control study 1-3. Am Rev Respir Dis 1992;146:1511-7

52 Schols AMWJ, Soeters PB, Mostert R, Pluymers RJ, Wouters EFM. Physiologic effects of nutritional support and anabolic steroids in patients with chronic obstructive pulmonary disease. Am J Respir Crit Care Med 1995; 152:1268-74

53 Woo J, Ho SC, Mak YT, Law LK, Cheung A. Nutritional status of elderly patients during recovery from chest infection and the role of nutritiona supplementation assessed by a prospective randomised single-blind trial. Age Ageing 1994;23:40-8.

54 Chiarelli A, Enzi G, Casadei A, Baggio B, Valerio A, Mazzoleni F. Very early nutrition supplementation in burned patients. Am J Clin Nutr 1990;51:1035-9.

55 Schroeder D, Gillanders L, Mahr K, Hill GL. Effects of immediate postoperative enteral nutrition on body composition, muscle function and wound healing. J Parenter Enteral Nutr 1991;15:376-83.

56 Hwang T, Huang S, Chen M. Early nasoduodenal feeding for the post biliary surgical patient. J Formosan Med Assoc 1991;90:993-7.

57 Sagar S, Harland P, Sheilds R. Early postoperative feeding with elementa diet. $B M J$ 1979;1:293-5.

58 Shulka HS, Raja R, Banu N, Gupta RM, Yadav RC. Enteral hyperalimentation in malnourished surgical patients. Indian J Med Res 1984;80 $339-46$

59 Evans WK, Nixon DW, Daly JM, Ellenberg SS, Gardner L, Wolfe E, et al. A randomized study of oral nutritional support versus ad lib nutitional intake during chemotherapy for advanced colorectal and non small cell lung cancer. J Clin Oncol 1987;5:113-24.

60 Smith RC, Hartemink RJ, Hollinshead JW, Gillet DJ. Fine bore jejunostomy feeding following major abdominal surgery: a randomised controlled trial. Br J Surg 1985;72:458-61.

61 Vonmeyerfeldt MF, Meijerink WJHJ, Rouflart MMJ, Builmassen MTH], Soeters PB. Perioperative nutritional support: a randomised clinical trial. Clin Nutr 1992;11:180-6.

(Accepted 8 May 1998)

\section{Correction}

The 1998 European Resuscitation Council guidelines for adult single rescuer basic life support

An error occurred in these guidelines by the Basic Life Support Working Group of the European Resuscitation Council (20 June, pp 1870-6). On p 1874 the paragraph before the heading "When to get help" should have read: "Finally, it must be emphasised that in spite of possible problems during training and in use, there is no doubt that placing an unconscious, breathing [not: non-breathing] victim into the recovery position can be life saving." 